\title{
Hemispherotomy for intractable epilepsy
}

\author{
Poodipedi Sarat Chandra, Vasantha M. Padma1', Gaikwad Shailesh², Bal Chandreshekar ${ }^{3}$, \\ Chitra Sarkar ${ }^{3}$, Manjari Tripathi
}

Departments of Neurosurgery, ${ }^{1}$ Neurology, ${ }^{2}$ Neuroradiology, ${ }^{3}$ Nuclear Medicine and Neuropathology, All India Institute of Medical Sciences, New Delhi, India.

\begin{abstract}
Context: Hemispherotomy is a surgical procedure for hemispheric disconnection. It is a technically demanding surgery. Our experience is presented here. Aims: To validate and compare the two techniques for hemispherotomy performed in patients with intractable epilepsies. Settings and Design: A retrospective study 2001-March 2007: Nineteen cases of hemispherotomies from a total of 462 cases operated for intractable epilepsy. Materials and Methods: All the cases operated for intractable epilepsy underwent a complete epilepsy surgery workup. Age range 4-23 years (mean 5.2 years), 14 males. The seizure frequency ranged from 2-200 episodes per day; four were in status; three in epilepsia partialis continua. The pathologies included Rasmussen's, hemimegelencephaly (unilateral hemispheric enlargement with severe cortical and subcortical changes), hemispheric cortical dysplasia, post-stroke, post-traumatic encephalomalacia and encephalopathy of unknown etiology. The techniques of surgery included vertical parasaggital approach and peri-insular hemispherotomy. Neuronavigation was used in seven cases. Results: Class I outcome [Engel's] was seen in 18 cases and Class II in one assessed at 32-198 weeks of follow-up. The four patients in status epilepticus had Class I outcome. Four patients had an initial worsening of weakness which improved to preoperative level in five to eight weeks. Power actually improved in three other patients at 32-36 weeks of follow-up, but hand grip weakness persisted. In all the other patients, power continued to be as in preoperative state. Cognitive profile improved in all patients and 11 cases returned back to school. Conclusions: Both techniques were equally effective, the procedure itself is very effective when indicated. Four of our cases were quite sick and were undertaken for this procedure on a semi-emergency basis.
\end{abstract}

Key words: Epilepsia partialis continua, epilepsy surgery, hemimegelencephaly, hemispherotomy, Rasmussen's syndrome, India, developing country

Functional hemispherotomy is indicated in patients with intractable epilepsy with a diffuse unicerebral pathology. Among the various choices available for epilepsy surgery, this procedure provides the highest rate of seizure control (average 77-80\%, Class I Engel) when performed in properly indicated patients. ${ }^{[1,2]}$ This has replaced the more invasive hemispherectomy ${ }^{[3,4]}$ as the latter not only leads to more blood loss, but is also associated with significantly higher rates of hydrocephalus, cerebral hemosiderosis, and sudural collections. After its first description by Rasmussen, ${ }^{[5]}$ functional hemispherotomy gained gradual popularity with two major techniques having been described: a vertical parasaggital approach described by Delalande $\mathrm{e}^{[6-8]}$ and a peri-insular technique described by Villemure ${ }^{[9,10]}$ and later more modifications being described. ${ }^{[11,12]} \mathrm{A}$ number of other techniques (especially some describing a less invasive route) have been developed by various authors, but all of them are based on the two surgical principles described above i.e. hemispherotomy performed either through a trans-cortical transventricular route (Delalande) or through a perisylvian access (Villemure). The authors discuss their own experience with both procedures and present the results of their cases.

\section{Materials and Methods}

This is a retrospective study from March 2001 through March 2007 at the department of Neurosurgery, All India Institute of Medical Sciences, New Delhi. The data was retrieved from the institute's medical records section, OT register, and OT notes. A total of 19 patients underwent hemispherotomy from the total number of 462 cases subjected to epilepsy surgery. All the patients were subjected to a complete epilepsy surgery evaluation: detailed history and clinical examination, electroencephalography (EEG), long-term video EEG (recording at least three events) and high-quality magnetic resonance imaging (MRI) scan [including spoiled gradient recalled (SPGR) acquisition, and Fluid-attenuated inversion recovery (FLAIR) sequences 
in oblique coronal planes 3-mm thick, perpendicular to the principal axis of the hippocampal formation). Gadolinium enhancement was used if a structural pathology was suspected (done in six cases). An interictal single photon emission computed tomography (SPECT) study was done using HMPAO. In patients with normal imaging and non-concordant VEEG and MRI, an ictal SPECT was done using Tc-ECD. Ictal and interictal SPECT subtraction (SISCOS) and co-registration with MR imaging (SISCOM) were also performed when indicated (in eight cases).

Patient population: Age raged from 4-23 years, with a mean age of 5.2 years and a median

of 6.2 years. They were 14 males. The seizure frequency ranged from 2-200 episodes per day. The average frequency was 12.8 episodes per day (median 28.2). The mean age of onset of seizure was 2.1 years (SD 3.6 years, range five months-8.2 years). Four patients were in status (of these, one patient had to be paralyzed and ventilated before undertaking surgery on a semi-emergency basis). Three had epilepsia partialis continua (pts 13,16,17: Table 1). Out of the remaining $12 / 19$ patients, five patients were hemiplegic on the affected side but were able to stand and even walk with support due to the presence of spasticity (pts 9-13, 18; Table 1). All the seven other patients were hemiparetic (pts 1-7; Table 1) and had a power varying from 3-4+/5. Three of the patients had a proportionately better upper limb power as compared to the lower limb power, with a relatively better preserved 'pincer grip' $(4+/ 5)$ (ability to oppose the thumb and the index finger)(pts 1-3; Table 1). Four patients had better preserved lower limb power as compared to the upper limb with a weaker pincer grip (pts 4-7, Table 1).

Surgical procedures: Of the 19 cases, eight patients were subjected to a vertical parasaggital approach and the rest to a peri-insular approach. ${ }^{[11]}$ Five patients underwent a left-sided procedure. Neuronavigation was used in seven cases.

Vertical parasaggital approach [VPH]: Here the patient was positioned supine with head flexed by about 30-40 degrees fixed rigidly on a three-pin clamp. A parasaggital fronto-parietal craniotomy of size $5 \times 5$ $\mathrm{cm}$ was performed centered on the coronal suture. A $3 \times 3 \mathrm{~cm}$ cortical corridor was created till the body of the lateral ventricle. Under microscope, hemispheric

\begin{tabular}{|c|c|c|c|c|c|}
\hline $\begin{array}{l}\text { Age (years) of onset of } \\
\text { seizure/age of surgery } \\
\text { /Seizure freq/ sex (M/F) } \\
\text { EPC: Epilepsia partialis } \\
\text { continua }\end{array}$ & $\begin{array}{c}\text { Power } \\
\text { UL = upper limb } \\
\text { LL = lower limb } \\
\text { NA = Not assessable } \\
\text { *in status } \\
\text { Pincer's: preserved } \\
\text { [+] / weak [-] }\end{array}$ & $\begin{array}{l}\text { Side of Surgery } \\
\text { L = left, R = right } \\
\text { Pathologies: } \\
\text { Rass, CD, } \\
\text { HEMIMEG, PS, } \\
\text { PTE, UNK }\end{array}$ & $\begin{array}{c}\text { Procedure } \\
\text { VPH = vertical } \\
\text { parasaggital } \\
\text { PIH = peri } \\
\text { insular app. } \\
8 \mathrm{VPH} \\
11 \mathrm{PIH}\end{array}$ & $\begin{array}{c}\text { Outcome } \\
\text { P=Power } \\
\text { L=Language } \\
\text { + improved } \\
\text {-worsened } \\
\text { S: same } \\
\text { Engel's score: } \\
\text { ES [I, II] }\end{array}$ & $\begin{array}{l}\text { Complications } \\
\text { [All transient, } \\
\text { treated } \\
\text { appropriately] }\end{array}$ \\
\hline 1.1/ 4.0/4-10 per day/M & UL>LL, Pincer - & $\mathrm{R} ;$ Rass & VPH & $P+/ E[I]$ & $\begin{array}{l}\text { Wound gape, } \\
\text { subdural hygroma } \\
\text { (reqd burr hole at } 2 \\
\text { months post op) }\end{array}$ \\
\hline 0.4/ 4.8/40-50 per day/F & UL>LL, Pincer - & L; Rass & $\mathrm{PIH}$ & $\mathrm{P}+/ \mathrm{E}[\mathrm{I}] / \mathrm{L}-$ & nil \\
\hline $0.7 / 5.2 / 2-10$ per week/M & UL>LL, Pincer - & R; HEMIMEG & $\mathrm{PIH}$ & $\mathrm{P}+/ \mathrm{E}[\mathrm{I}]$ & nil \\
\hline 6.0/ 23.0/2-3/per week/M & LL>UL, Pincer + & $\mathrm{R} ; \mathrm{CD}$ & VPH & P-/E[I] & nil \\
\hline $1.8 / 6.0 / 2-4$ per month & LL>UL, Pincer + & L; Rass & VPH & P-/E[I]/L- & nil \\
\hline 6.0/ 8.0/4-6 per week/M & LL>UL, Pincer - & R; HEMIMEG & $\mathrm{PIH}$ & $\mathrm{P}-/ \mathrm{E}[\mathrm{I}]$ & nil \\
\hline 8.2/ 9.0/ 20-30 per day/F & LL>UL, Pincer + & R; HEMIMEG & $\mathrm{PIH}$ & P-/E[I] & nil \\
\hline $2.5 / 4.8 /$ Status $>200$ per day/M & $\mathrm{NA}^{*}$ & $\mathrm{R} ;$ Rass & VPH & $\mathrm{Ps} / \mathrm{E}[\mathrm{I}]$ & nil \\
\hline 5.0/ 6.6/12-20 per week/M & Hemiplegic & $\mathrm{R} ; \mathrm{PS}$ & VPH & $\mathrm{PS} / \mathrm{E}[\mathrm{I}]$ & $\begin{array}{l}\text { Deep venous } \\
\text { thrombosis, } \\
\text { hydrocephalus } \\
\text { (reqd shunt at } 3 \\
\text { months post } \\
\text { surgery) }\end{array}$ \\
\hline 1.3/4.0/3-4 per month/M & Hemiplegic & R; HEMIMEG & VPH & $\mathrm{Ps} / \mathrm{E}[\mathrm{I}]$ & nil \\
\hline 2.7/ 6.5/1-4 per month/M & Hemiplegic & R; Rass & VPH & $\mathrm{Ps} / \mathrm{E}[\mathrm{I}]$ & nil \\
\hline 0.5/ 9.2/15-20 per day/M & Hemiplegic & L; UNK & $\mathrm{PIH}$ & Ps/E[II]/L- & nil \\
\hline $0.6 / 6.1 / \mathrm{EPC} / \mathrm{M}$ & $\mathrm{NA}^{*}$ & $\mathrm{R} ;$ Rass & VPH & P-/E[I] & nil \\
\hline 1.2/ 8.0/Status >200 per day/F & $\mathrm{NA}^{*}$ & L; PS & $\mathrm{PIH}$ & $\mathrm{Ps} / \mathrm{E}[\mathrm{I}]$ & nil \\
\hline $1.3 / 6.0 /$ Status $>200$ per day ventilated/F & $\mathrm{NA}^{*}$ & $\mathrm{R} ; \mathrm{PS}$ & $\mathrm{PIH}$ & $\mathrm{Ps} / \mathrm{E}[\mathrm{I}]$ & nil \\
\hline $3.2 / 7.2 / \mathrm{EPC} / \mathrm{M}$ & $\mathrm{NA}^{*}$ & $\mathrm{R} ;$ Rass & $\mathrm{PlH}$ & $\mathrm{Ps} / \mathrm{E}[\mathrm{I}]$ & $\begin{array}{c}\text { Subdural hygroma, } \\
\text { meningitis }\end{array}$ \\
\hline 6.2/ 9.7/EPC/F & $\mathrm{NA}^{*}$ & L; Rass & $\mathrm{PIH}$ & $\mathrm{Ps} / \mathrm{E}[\mathrm{I}]$ & nil \\
\hline $6.4 / 18.4 / 6-8$ per week/M & Hemiplegic & R; PTE & $\mathrm{PlH}$ & $\mathrm{Ps} / \mathrm{E}[\mathrm{I}]$ & nil \\
\hline $1.2 / 9.1 /$ Status $>200$ perday/M & $\mathrm{NA}^{*}$ & $\mathrm{R} ; \mathrm{PS}$ & $\mathrm{PIH}$ & $\mathrm{Ps} / \mathrm{E}[\mathrm{I}]$ & nil \\
\hline
\end{tabular}

Note: Patients have not been listed in chronological order 
disconnection was carried out lateral to the thalamus and the basal nuclei. For further details of the technique, the reader is referred to Delande et al. ${ }^{[6,8]}$.

Peri-insular approach [PIH]: The surgical principle is based on the peri-insular access described originally by Villemure et al..$^{[9-10]}$ Here a fronto-temporal craniotomy is performed centered over the Sylvian fissure. A 'C'-shaped cortical corridor is created to the lateral ventricle. Disconnection is then performed connecting the internal surface of the ventricle till the medial part of the hemisphere all around the ventricle. At the end the central peri-insular 'block' is then excised as close to the sphenoid ridge as possible.

The choice of surgical approach was decided by two main factors ${ }^{[1]}$ ventriculomegaly ${ }^{[2]}$ and a distance greater than $10 \mathrm{~cm}$ from the vertex till the temporal horn. The surgeon preferred a vertical parasaggital approach [VPH] if there was a significant ventriculomegaly and the distance between the vertex and temporal horn was less than $10 \mathrm{~cm}$. A peri-insular [PIH] approach was preferred otherwise. These indications were not very strictly adhered to. The senior author [PSC] generally preferred VPH in younger children. The main reason for [factor 1] was because ventriculomegaly facilitated a better as ventricular access through a narrow corridor . The cutoff distance of $10 \mathrm{~cm}$ [factor 2] was selected as this generally represents the furthest 'comfortable' working point on an operating microscope and a distance more than this generally makes hand maneuverability more difficult. Considering that the distance between the vertex and the temporal horn represents the maximal distance while performing a vertical parasaggital procedure, this factor was considered by the author. However, it is to be mentioned that this has been only based upon the surgeon's perception and not on any existential evidence. A more objective study would be required to clarify this. The author also preferred VPH in very small children as the size of the head was smaller in them, the size of the craniotomy used by the surgeon was smaller and the blood loss was also less (see results).

The details of these procedures have already been described in the literature. ${ }^{[2-12]}$ In the initial cases, neuronavigation [Stealth, Medtronic] was used, as this provided a good anatomical perspective and a better learning. Similarly, in the initial cases, a large craniotomy was performed, more experience helped us to reduce the size of the craniotomy. Following the surgery, a ventricular drain was left for $24 \mathrm{~h}$. This helped in draining out the blood-stained CSF, which the authors believe reduces the incidence of hemosiderosis. No conversion from one to the other procedure was required in any of the cases.

The completeness of the hemispherotomy was judged intra-operatively by the surgeon. Hemispherotomy was usually performed starting from the frontal end and
Table 2: Engel outcome grading for epilepsy ${ }^{[1]}$

Class I: free of disabling seizures

Class II: rare disabling seizures

Class III: worthwhile improvement

Class IV: no worthwhile improvement

then was extended to the temporal end. Tailed cotton patties or surgicel were placed serially along the depth of the disconnected hemisphere to confirm complete disconnection at the end of the surgery. Immediate postoperative plain computed tomography (CT) scan was performed in all cases within a week and MRI was performed at around one month of follow-up not only to confirm the disconnection but also to look for complications like hydrocephalus or a subdural collection.

Postoperative assessment: This was carried out using seizure outcome parameters of Engel ${ }^{[1]}$ [Table 2], assessment of motor weakness, language and cognition. Antiepileptic drugs were continued for one year and then tapered as per the discretion of the treating neurologist. A complete indigenous neuropsychological battery ${ }^{[13]}$ was used whenever feasible (16 patients). In three children who were severely retarded, only a basic assessment of memory and intelligence was performed. Assessment was performed in the immediate postoperative period, at seven days, one month, three months, six months, one year and then annually.

\section{Results}

Clinical semiology: From a total of 19 patients, (14 boys), five underwent a left hemispherotomy and the rest a right-sided procedure. The mean age of onset of seizure was 2.1 years (SD 2.29 years, range five months8.2 years), the mean age at hemispherotomy was 8.1 years (range 4-23 years). A majority of the patients were sick with a very high seizure frequency ranging from 2-200 per day. The mean preoperative delay after the onset of epilepsy was 9.2 years.

Surgical procedure and pathology: Eight underwent a VPH procedure and 11 a PIH [Table 1]. The etiologies included Rasmussen's, ${ }^{[8]}$ hemimegelencephaly, ${ }^{[4]}$ hemispheric cortical dysplasia, ${ }^{[1]}$ post-stroke, ${ }^{[4]}$ posttraumatic encephalomalacia ${ }^{[1]}$ and encephalopathy of unknown etiology. ${ }^{[1]}$ Between the two procedures, there was no difference in seizure outcome. There was also no necessity to convert one procedure into the other.

Seizure outcome: Follow-up ranged from 32-198 weeks (mean of 78 weeks). Eighteen patients had a Class I outcome and one patient had a Class II outcome. The latter patient was aged nine years, and pathology revealed nonspecific encephalopathy (patient no. 12; Table 1). Magnetic resonance imaging showed patchy signal changes in the healthy hemisphere too.

Motor outcome: The age of surgery and hemiparesis 
were found to be the most important factors to assess the postoperative outcome of weakness. In this regard, weakness of the upper limb particularly the "pincer grip" was important. In the three patients where the power improved following surgery, the ages were 4, 4.8 and 5.2 (patient nos. 1-3; Table 1) and all formed the younger age groups in the series. All these patients had a better preservation of the lower limb power as compared with the upper limb and were unable to perform the pincer's grip. In comparison to this, four patients had an initial worsening of power (patient nos. 4-7; Table 1). In three of these the pincer grip was well preserved and the lower limb power was proportionately more involved as compared to the upper limb. All these four patients also represented patients in the higher age range in the series (ages six, eight, nine and 23 years). Thus younger age of surgery and proportionately better preservation of the lower limb were factors found to be associated with better motor outcome. However, we do agree that the present series is too small to draw a reasonable conclusion.

Language outcome: Of the five patients who underwent a left-sided procedure, Functional MRI (fMRI) was performed in all before surgery to assess the bilateralism of motor movements. fMRI for motor activity only was included in this study. Language fMRI though performed was not utilized due to the unpredictability of interpretation of the data (due to absence of proper controls). Wada test was not done in any of the cases as it was not available at our institute. In four of these patients, motor power showed bilateral activity. This was the basis of assuming that the language may have also shifted to the other hemisphere. Following surgery, three patients developed language deficits (patient nos: $2,5,12$ ). One patient became completely mute and took around 12-18 weeks before he developed any word output. Two patients developed transient and partial deficits which improved in one to two weeks. It is to be noted that none of the patients developed any comprehension deficits.

Cognitive outcome: For neuropsychological evaluation, we used a customized battery drafted in Hindi. The reliability of the battery in terms of test-retest and interexaminer variance had also been established prior to use in our epilepsy surgery program. On both of these reliability tests, the reliability coefficients $(0.926$ and 0.967 , respectively) were significant at the $P=0.001$ level, which means that scores are stable over time and there is negligible interexaminer variance in seizure outcome. The details of these have been published earlier.

In cognitive faculties, all except three patients improved significantly ( $>2$ SD) and 11 returned back to school. Even in the three patients who were severely retarded, subjective improvement were reported by parents though not significant.
Complications: Seven complications developed in three patients. These included subdural hygroma (2), hydrocephalus (1), meningitis (1), wound gaping (1), deep venous thrombosis (2) [Table 1]. There was no mortality. Subdural hygromas developed in the initial cases, during the learning curve when more parenchyma was 'excised' while performing the hemispheric disconnection. This problem was overcome with reformation in the technique. Both the hygromas required a burr hole evacuation. One ultimately required a subduroperitoneal shunt. The patient with hydrocephalus required a shunt too. All the complications resolved with appropriate treatment.

\section{Discussion}

Hemispherectomy as a procedure for intractable epilepsy has been described earlier in Indian literature. ${ }^{[12]}$ Hemispherotomy while has been described either sporadically or as part of a large series has not been compiled as a separate entity. ${ }^{[13-15]}$ The present paper is perhaps the first documented paper in Indian literature on a comparatively large series of this relatively uncommonly performed procedure with a follow-up of up to four years.

The technique of VPH has been developed by Delande, ${ }^{[6-8]}$ while the PIH has been developed by Villemure $^{[10]}$ and later modified by many others. ${ }^{[11,12]}$ Both the procedures have demonstrated equal efficacy in terms of morbidity and seizure outcome.

The senior author [PSC] performed the first procedure using the vertical parasaggital approach. During the initial stages neuronavigation [Medtronic stealth; used in seven cases] was utilized to orient the surgeon to the anatomy and provide a smooth learning curve. Subsequently, the peri-insular hemispherotomy was utilized. Presently, the author prefers both procedures as per an approximate guideline given below.

Since both techniques of surgeries (VPH and PIH) have been performed by the same surgeon in the present series, some approximate guidelines have been proposed for either technique. Generally the authors have found that in small children, a VPH was more useful as it involves a smaller incision. Moreover, the structures required to be disconnected being at a greater depth in this procedure are more easily accessed in small children (with small heads). The presence of ventriculomegaly makes this technique easier. As a guideline, a distance of less than $10 \mathrm{~cm}$ between the vertex (point of entry) and the temporal horn has been used as a rough cutoff point in deciding to perform VPH. The reason to select this point is because this is the upper limit of comfortably working under the microscope through a cortical incision. A distance of more than $10 \mathrm{~cm}$ has been associated with greater difficulty in performing VPH. While we agree that these 
parameters have not been described elsewhere, these have been the impressions of the surgeon using both the techniques. A PIH involves a larger scalp incision and the structures to be disconnected are more easily accessed, thus the authors felt that this technique is more convenient for older children. Thus pathologies like hemimegelencephaly with large hemisphere, abnormal tissue and 'chinked' ventricles would be more easily disconnected with a PIH while post-stroke hemispheres with a large ventricle and an atrophied cortex would be better dealt with a VPH. It is to be emphasized again that these are only approximate guidelines suggested by authors for epilepsy surgeons in order to use both the techniques optimally.

Concerning the efficacy on seizures, for VPH (mostly described by one author $\left.{ }^{[6-8]}\right)$ about $74 \%$ of the patients were seizure-free with no seizure recurrence in a longterm follow-up.

Globally, with lateral hemispherotomy, the rate of patients achieving Class I Engel's outcome ranges between 68 and 88\%. ${ }^{[9,13,16-24]}$ For the modified PIH, the seizure-free outcome in the first two postoperative years has been reported to be 82.7 and $66.7 \%$. However, this outcome decreased at five years following surgery to 60.5 and $62.5 \% .^{[13]}$ The largest study on seizure outcome was reported by Holthausen et al., ${ }^{[20]}$ involving 333 hemispherectomies from 13 different centers with a minimum follow-up period of six months. The percentage of seizure-freedom was better in the patients who underwent hemispherotomy. (85\% Class I) and in the group of patients who had pathologies like Rasmussen, Sturge-Weber, and vascular insults (94\% Class I). The other group of patients, including those with cerebral dysplasia and other etiologies (sequel of infections, post meningitis, post encephalitis) became seizure-free in a much smaller proportion $(68 \%)$.

Following the starting of the epilepsy program ${ }^{[15-18]}$ at our center, the first hemispherotomy was performed by the senior author [PSC] in 2001 after which 19 cases have been added. In the present series, 18/19 patients have been seizure-free with a varying degree of follow-up of upto 4 years. In one patient, while the generalizations stopped, he continued to have auras. The parents also reported witnessing occasional 'focal jerks' in the night while sleeping.

The present series may seem to have a very high rate of seizure-free outcome as compared with the literature. The reasons contributing is likely to be due ${ }_{[1]}$ to a larger number of cases with a longer follow-up required to make a more judicial assessment. Thirteen out of 19 cases were good outcome pathologies $^{[14-16]}$ e.g (Rasmussen.s, post stroke). We have used an indigenously developed neuropsychological battery $^{[25]}$ in all except three children who were severely retarded. All the 16 patients improved significantly in their memory and intelligence scores (more than 2 SD) and 11 returned back to school.

In our series, five patients had a left-sided pathology. Since we do not have Wada's test available at our center, only functional MRI was performed. Functional MRI with sensorimotor, visual and language paradigms was performed but we have used only the sensorimotor data for interpretation due to lack of proper standardization for the other two parameters. Here $4 / 5$ patients showed bilateral cortical activity. Two of these patients developed transient language problems following surgery. We do agree the shortcoming of this technique as compared with the 'gold standard' Wada's test, but are newer software modules with e.g. with real time fMRI does seem to hold a good promise. ${ }^{[16,17]}$ The fMRI used in our series was based on the assumption that language too may shift to the opposite hemisphere along with the motor functions. However, we do also reiterate that whatever would have been the results on fMRI, we would have still gone ahead with the surgical procedure as all these patients were quite sick and would have required the surgical procedure anyway. Furthermore, the role of either Wada or fMRI in hemispherotomy is unclear and does not seem to affect the surgical decisions. We are at present developing proper language modules and controls to assess language fMRI for patients evaluated henceforth.

Postoperative mortality and morbidity has been reported in detail by Cook et al. ${ }^{[18]}$ and Jonas et al., ${ }^{[19]}$ who compared the advantages and disadvantages associated with each subtype of PIH (anatomic, functional, and modified lateral hemispherectomy). They demonstrated that modified PIH seemed to have the least complication rate (11-35\%) and a reduced necessity of shunt (9.4\%). In VPH, the necessity for shunt placement was $16 \%$. Generally the need for shunt has been more commonly seen in children with hemimegalencephaly. In our series, one patient developed hydrocephalus and two subdural hygromas; all of them requiring surgical treatment.

\section{Conclusions}

Hemispherotomy is a surgical procedure of hemispheric disconnection that has a low rate of complications, andseems to be as safe as other procedures for epilepsy surgery. Moreover, this procedure allows highest seizure-free outcome (in our series 94\%) even though we do agree that our series is small to draw a reasonable assessment. A larger number with a longer follow-up will prove to highlight the long-term efficacy in the Indian scenario. We do acknowledge the limitations of this being a retrospective study.

Ethical clearance: The study included surgical procedures well accepted in the literature for these pathologies hence did not merit any ethical clearance. 


\section{Acknowledgment}

The authors wish to acknowledge Ms Prarthana for having helped in preparing the manuscript.

\section{References}

1. Engel J. Outcome with respect to epileptic seizures. In: Engel J, editor. Surgical treatment of the epilepsies. New York: Raven Press; 1987. p. $553-71$.

2. Wen HT, Rhoton AL Jr, Marino R Jr. Anatomical landmarks for hemispherotomy and their clinical application. J Neurosurg 2004;101:747-55.

3. Krynauw RA. Infantile hemiplegia treated by removing one cerebral hemisphere. J Neurol Neurosurg Psychiatry 1950;13:243-67.

4. Lhermitte J. Ultimate results of hemispherectomy in cases of infantile cerebral hemiatrophy productive of epilepsy. Encéphale [in French] 1928;23:314-23.

5. Rasmussen T. Hemispherectomy for seizures revisited. Can J Neurol Sci 1983;10:71-8

6. Delalande O, Pinard JM, Basdevant C, Gauthe M, Plouin P, Dulac O. Hemispherotomy: A new procedure for central disconnection. Epilepsia 1992;33:99-100.

7. Delalande O, Fohlen, Jalin, Pinard JM. From hemispherectomy to hemispherotomy. In: Lüders HO, Comair YG, editors. Epilepsy surgery. 2nd ed. Philadelphia: Lippincott Williams and Wilkins; 2001. p. 741-6.

8. Delalande O, Bulteau C, Dellatolas G, Fohlen M, Jalin C, Buret V, \& al. Vertical parasagittal hemispherotomy: Surgical procedures and clinical longer outcomes in a population of 83 children. Neurosurgery 2007;60:2.

9. Villemure JG, Mascott CR. Peri-insular hemispherotomy: Surgical principles and anatomy. Neurosurgery 1995;37:975-81.

10. Villemure JG, Vernet O Delalande O. Hemispheric disconnection: Callosotomy and hemispherotomy. In: Cohadon F, editor. Advances and technical standards in neurosurgery. vol. 26, Vienna: Springer-Verlag; 2000. p. 25-78.

11. Schramm J, Kral T, Clusmann H. Transsylvian keyhole functional hemispherectomy. Neurosurgery 2001;49:891-901.

12. Daniel RT, Chandy MJ. Epilepsy surgery: Overview of forty years experience. Neurol India 1999;47:98-103.

13. Nayak D, Abraham M, Kesavadas C, Radhakrishnan K. Lingual epilepsia partialis continua in Rasmussen's encephalitis. Epileptic Disord 2006;8:114-7.

14. Raghavendra S, Krishnamoorthy T, Ashalatha R, Nayak SD,
Radhakrishnan K. Hemimegalencephalic appearance of normal hemisphere in unilateral heterotopia and absent corpus callosum. Epilepsy Behav 2006:9:363-6.

15. Pandian JD, Thomas SV, Santoshkumar B, Radhakrishnan K, Sarma PS, Joseph S \& al. Epilepsia partialis continua: A clinical and electroencephalography study. Seizure 2002;11:437-41.

16. Liégeois F, Cross JH, Gadian DG, Connelly A. Role of fMRI in the decision-making process: Epilepsy surgery for children. J Magn Reson Imaging 2006;23:933-40.

17. Kesavadas C, Thomas B, Sujesh S, Ashalata R, Gupta AK, Radhakrishnan K, \& al. Real-time functional MR imaging (fMRI) for presurgical evaluation of paediatric epilepsy. Pediatr Radiol 2007;37:96474.

18. Cook SW, Nguyen ST, Vinters HV, van de Wiele BM, Harrison RE, Mathern GW, $\mathbb{A}$ al. Cerebral hemispherectomy in pediatric patients with epilepsy: Comparison of the three techniques by pathological substrate in 115 patients. J Neurosurg 2004;100:125-41.

19. Jonas R, Nguyen S, Hu B, Shields WD, Vinters HV, Mathern GW, \& al. Cerebral hemispherectomy: Hospital course, seizure, developmental, language, and motor outcomes. Neurology 2004;62:1712-21.

20. Holthausen H, May TW, Adams TB, Andermann F, Villemure JG, Wyllie E, \& al. Seizures posthemispherectomy. In: Tuxhorn I, Holthausen H, Boenig H, editors. Paediatric epilepsy syndromes and their surgical treatment. London: John Libbey; 1997. p. 749-73.

21. Sarat Chandra P, Tripathi M, Gaikwad S, Kalra V. Epilepsy surgery in children: Whom, when and why? Indian J Pediatr Supp 2007;73:S43-7.

22. Sarat Chandra P, Mathern GW. Epilepsy surgery in children. 2006. Available from: http://www.medlink.com/

23. Deb P, Sharma MC, Gaikwad S, Tripathi M, Chandra PS, Sarkar C \& al. Neuropathological spectrum of Rasmussen encephalitis. Neurol India 2005;53:156-61

24. Sarkar C, Sharma MC, Chandra PS, Tripathi M, Gaikwad S, Bal CS, etal. Neuropathological spectrum of lesions associated with intractable epilepsies: A 10-year experience with a series of 153 resections. Neurol India 2006;54:144-51

25. Sanyal SK, Chandra PS, Tripathi M, Jain S, Padma MV, Mehta VS, e al. Memory and intelligence outcome following surgery for intractable temporal lobe epilepsy: Relationship to seizure outcome and evaluation using a customized neuropsychological battery. Epilepsy Behay 2005;6:147-55.

Accepted on 14-04-2008

Source of Support: Nil, Conflict of Interest: None declared. 